\title{
NACIONALISMO POPULISTA Y DESENCANTO. POÉTICAS DE MODERNIDAD EN LA NARRATIVA DE GUILLERMO MENESES
}

POR

JAVIER LASARTE VALCÁRCEL

\section{DOS AGUAS MODERNAS}

Reducir la modernidad literaria a la prosecución de la autonomía o la racionalización "propiamente" artísticas, o a la presencia de nuevas subjetividades y de nuevas formas de objetivación textual, obviando los cambios de situación relaciones, tipo y función del intelectual así como las modalidades específicas que adquiere la literatura al acompañar los procesos de formación de las nacionalidades, tendría a estas alturas poco sentido. ${ }^{1}$ Más aun en casos como los de las literaturas latinoamericanas, enmarcadas en procesos inestables e inconclusos - sólo más que otros-y como los de sus escritores, a menudo enfrentados a la permanente tensión de responder a los requisitos de lo actual artístico sin poder deshacerse de un cierto grado de responsabilidad pública que - quiera o no- lo liga a la arena de la cosa social.

Guillermo Meneses ha sido presentado en distintas épocas como paradigma de los dos modelos básicos de la modernidad literaria venezolana. Estos modelos podrían tipificarse a grandes rasgos y con todas las variantes que se quieran, como aquél que tiene por norte principal la reflexión sobre la nacionalidad y el que centra el trabajo discursivo en torno a la idea de una relativa autonomía artística. El Meneses que se iniciara el año 30 publicando en la revista Elite atípicos relatos - "Elogio de la velocidad" o "Juan del Cine"-

\footnotetext{
${ }^{1}$ Aquí acogemos la idea de postmodernidad postulada por George Yúdice al concebirla "no como una nueva episteme que sucede a la modernidad sino como la comprensión de que la modernidad consiste en 'múltiples respuestas/propuestas', es decir, que hay múltiples modernidades, múltiples formaciones sociales y culturales que constituyen la modernidad". "¿Puede hablarse de postmodernidad en América Latina?", Revista de Crítica Literaria Latinoamericana XV/29 (1989) 108. También Graciela Montaldo ronda esta idea en su artículo "De pronto el campo", Punto de Vista, 43 (agosto, 1992) 21-25, cuando propone leer la gauchesca y aquellos discursos que construyen la tradición como una de las formas propias de la modernidad, impensable fuera del proceso de modernización de fines del XIX. Y el que suscribe, de algún modo, partiendo de un principio parecido, también trató de desarrollarla en una ponencia presentada en el III Congreso de Culturas Hispánicas (Santiago de Chile, agosto, 1992), "Poéticas de la primera contemporaneidad y cambio intelectual en la narrativa venezolana", al intentar mostrar el carácter moderno aunque obviamente diverso de autores como Rómulo Gallegos y Teresa de la Parra.
} 
con aires de una vanguardia vivida de manera efímera o peculiar que tuviera una temprana popularidad con La balandra "Isabel" llegó esta tarde (1934) y que hacía frecuentes elogios a la empresa narrativa de Gallegos y al Uslar Pietri de Las lanzas coloradas, llegaría finalmente tras la publicación de la novela Campeones (1939) a ser consagrado por sus congéneres como el "Gorki venezolano". ${ }^{2}$ Algunas décadas más tarde a partir de los años sesenta y hasta hoy el Meneses del cuento "La mano junto al muro" (1952) y la novela $E l$ falso cuaderno de Narciso Espejo (1953) será exhibido y reivindicado como el "otro" literario de sí mismo. Para importantes sectores de la intelectualidad venezolana el Meneses último se ha convertido en el oficiante mayor de un ejercicio que tiene por objeto el destierro de cuanto suene a nacionalismo en el sustituto antagónico de Gallegos en el panteón de los nuevos dioses de la patria literaria. ${ }^{3}$

Vistos desde afuera La balandra "Isabel" ... y "La mano junto al muro" de similar base temática, producen la impresión de ser relatos escritos por dos autores diferentes, y en cierto modo así es. En otras partes he intentado mostrar hasta que punto hay dos Meneses (1930-1945 y 1946-1962) y como el segundo parodia al primero. ${ }^{4}$ En sentido estricto, desde luego no se trata de dos autores, sino de un cambio que, por la vía del desencanto político en el Meneses militante, se traduce en un drástico viraje en la poética narrativa del escritor. ${ }^{5}$ La situación no es ajena a otros ámbitos del continente pues el caso de la trayectoria narrativa de Guillermo Meneses guarda no pocas correspondencias - temáticas y de poética- con la que podría diseñarse del Juan Carlos Onetti de antes y después de $E l$ pozo. El vi(r)aje es el siguiente: el punto de partida es una narrativa de corte populista evidentemente vinculada al criollismo precedente que ubica sus escenarios en la encrucijada histórica del tránsito del mundo rural al urbano, de intención social didáctica y moralizante reformulada - eso sí - en su aspecto narrativo por los aires de las innovaciones técnicas y temáticas de la época e incluso por el impacto del lenguaje cinematográfico; el de llegada, la narrativa del desencanto, que instala el discurso en un espacio que se pregunta por los límites y el carácter de la escritura y revisa la relación de su quehacer con el mundo de la historia toda vez que el escritor ha asumido su condición de excluido o derrotado. El viaje ilustra lo que han sido los dos modelos dominantes de la contemporaneidad literaria en

\footnotetext{
${ }^{2}$ José Fabbiani Ruiz, “Campeones de Guillermo Meneses”, Revista Nacional de Cultura 6 (1939) 47-8.

${ }^{3}$ Acaso este tipo de actitud no se dé con tanta radicalidad en otros países latinoamericanos, pero si comparte la común plataforma del espíritu asentado por la percepción sesentista que suscitó el fenómeno de la "nueva novela" - p.e. Carlos Fuentes-el "boom", que usó como chivos expiatorios predilectos las llamadas "novelas de la tierra" y del "realismo social".

${ }^{4}$ Véase "Guillermo Meneses: hacia una caracterización de su narrativa", Voz y Escritura. Revista de Estudios Literarios 2-3 (1989-1990) 65-91; "Meneses parodia y desencanto", Imagen 100-64 (abril, 1990) 12-13; y el "Prólogo" a Diez cuentos (Caracas: Monte Ávila, 1991) 7-32.

${ }^{5}$ De entrada no estoy ganado para este tipo de interpretaciones que algunos consideraran salvajes pero en este caso, como en otros, necesito hacer una excepción ante lo que me resulta inocultable. $\mathrm{El}$ hecho no es insólito para la época, pues aunque no sea lo mismo ya medio siglo antes el narrador modernista había ilustrado temáticamente el desencanto político del intelectual en sus novelas. Véase Paulette Silva, "La narrativa venezolana de la época del modernismo", Revista Chilena de Literatura 40 (1992) 41-56.
} 
Venezuela y buena parte de Latinoamérica: el de los nuevos criollismos o regionalismos que surgen con la vanguardia — cada vez más alejados de la "tierra" y ubicados en el mundo de la ciudad - y el realismo social cuya situación privilegiada sería inútil negar hasta los años cuarenta, y el que comienza a consolidarse a mediados de siglo cuando el criollismo tuerce el rumbo hacia realismos mágicos o maravillosos, Borges, Bioy Casares, Arreola o Cortázar impulsan diversas fantásticas y un nuevo tipo de realismo - urbano crítico celinesco o sartriano- abrirán puertas a las poéticas de décadas más recientes.

\title{
Andreiev, Gallegos y Bárbara La Marr. La vanguardia tibia (1930-1934)
}

La relación que establece un sector intelectual latinoamericano con los modelos artísticos de vanguardia - básicamente europeos- que conoce directa o indirectamente en los años veinte y treinta es en no pocos casos conflictiva o confusa. Desde luego la vivencia de novedad y cambio es genuina y obedece a una instancia diferente del proceso modernizador que venía confrontando el escritor desde finales del XIX. Pero lo que genera el conflicto o la confusión de parte de algunos escritores vanguardistas es el modo en que procesarán el contacto con los modelos metropolitanos: a veces sólo asumidos en forma parcial y en diversos grados en las mecánicas discursivas, pero aún predominantemente articulados a la raíz que ofrece la propia tradición narrativa. Es lo que hace que al menos en términos cuantitativos nuestras vanguardias tengan un inequívoco sello nacionalista, y que la novedad se presente como una vuelta de tuerca no ruptural de la tradición cultural en la que - aunque críticamente - se reconocen.

El mismo Meneses, en su prólogo de 1967 a la edición de su antología Diez cuentos, plantea el modo en que se vivió este acercamiento a diversos modelos culturales. De la relación de lecturas que a modo de aprendizaje - "influencias", como diría el propio Meneses- orientaban la reflexión del escritor y de algunos de sus colegas, se desprende este modo particular de percibir la idea de vanguardia:

\begin{abstract}
Allá por los años de 1930 estábamos los jóvenes dentro de lo que considerábamos la "vanguardia". Nos empapábamos de todo lo que nos hacía pasar Madrid (sobre todo a través de la Revista de Occidente). Ese Madrid de entonces estaba en sana relación europea, de tal manera que no nos era extraño lo francés, lo alemán, lo italiano, lo yanqui, que recogía para su revista Ortega. Leíamos a Mann, a Huxley, a Faulkner, a Jung, a Hesse, a Hauptmann, sin olvidarnos de Proust y sin abandonar a Zola, a Queiroz, a Dostoievski, a Balzac y a nosotros mismos [subrayado añadido]. ${ }^{6}$
\end{abstract}

De hecho por testimonios de Meneses y otros, habría que sumar al bagaje lecturas como las de Azorín, Ricardo León, Gorki o Andreiev. El aspecto tan poco "vanguardista" de la muestra mencionada, casi mayoritariamente decimonónica, se refuerza cuando Meneses en una entrevista algo posterior a su prólogo confiesa el peso mayor que por esa época

\footnotetext{
${ }^{6}$ Guillermo Meneses, Diez cuentos, $3^{\mathrm{a}}$ edición (Caracas: Monte Ávila, 1991) 44. De aquí en adelante cualquier cita tomada de esta edición se limitará a señalar las siglas y el número de página.
} 
tuvieron las lecturas de Hauptmann, Zola y Eça de Queiroz. ${ }^{7}$ La simultánea relación con la propia tradición literaria más o menos inmediata queda expresada del siguiente modo en el prólogo del autor a sus Diez cuentos:

... teníamos lecturas venezolanas de mucho respeto: conocíamos bien lo que habían hecho escritores tan dispares como Díaz Rodríguez y José Rafael Pocaterra y nos habíamos acercado igualmente aunque con menor interés a Urbaneja Achelpohl. Estimábamos a Gallegos —el de La trepadora en especial ...

Además apareció entonces Las lanzas coloradas de hombre tan cercano como Arturo Uslar Píetri. Tanto en Gallegos como en Uslar quisimos observar cómo lo que teníamos por criollismo podía lograr formas que lo unían a las nuevas tendencia literarias ( $D c 45$; subrayado añadido).

Estas últimas líneas expresan en forma condensada lo que más adelante expondrá con mayor detenimiento la particular poética vanguardista del primer Meneses y sus similares: ${ }^{8}$

Tuvo que haber el desarrollo de la vanguardia tal como la sentimos -el uso de las imágenes y metáforas relumbrantes y promovidas por el mundo civilizado que considerábamos nuestro por contemporáneo-y, al mismo tiempo, se presentó una nueva manera de comprender las "cosas venezolanas", de tal modo que no eran para nosotros motivos de simple pintoresquismo sino conocimiento de los problemas que mantenían a Venezuela en un estado social y en un ordenamiento político que considerábamos insoportable. El criollismo anterior era de turistas. El nuestro lo teníamos dentro como testimonio (Dc 45).

Esta línea de cruce que tiende a conjugar antes que a oponer lo local o lo nacional con lo cosmopolita o mejor lo internacional -inconcebible sin las operaciones mentales que iniciaran desde el modernismo pensadores como Martí y ya entrado el siglo XX otros como Henríquez Ureña o Reyes- es característico de los años de la vanguardia y define el proyecto de un importante sector de la intelectualidad artística latinoamericana de entonces. (Piénsese si no en Martín Fierro o la Revista de avance.)

Otro rasgo específico que podría remarcarse es el carácter innovador más que ruptural - "nuevo" pero no "opuesto"- del proyecto vanguardista menesiano y de la tendencia predominante de la vanguardia venezolana. Un buen ejemplo de este vanguardismo en cierto modo tan poco vanguardista lo ofrece Meneses en algunos de sus primeros textos, ajenos a los temas y personajes habituales en él durante esa década: "Juan del Cine" (1930) y "Adolescencia" (escrito en 1934 pero publicado en Tres cuentos venezolanos de 1938). En ellos se aborda como asunto la vida interior del adolescente: uno, Juan del

\footnotetext{
${ }^{7}$ Mario Szichman, "Guillermo Meneses, revisitado", Suplemento Cultural de Últimas Noticias (Caracas, 7 de enero de 1979).

${ }^{8}$ En este grupo puede mencionarse lo escrito por narradores como Carlos Eduardo Frías, Nelson Himiob, José Salazar Meneses o Ramón Díaz Sánchez, por no mencionar las últimas novelas de Enrique Bernardo Núñez, perteneciente a una promoción anterior y de escasa difusión entre los jóvenes vanguardistas, aunque más audaz que la mayoría de ellos.
} 
Cine, fascinado y alienado por el mundo nuevo y tentador del celuloide, vive para amar en la pantalla y el espejo a Bárbara La Marr o Greta Garbo; el otro, Julio Folgar, sencillamente amplía el horizonte libresco del anterior al pretender convertirse en figura satánica y rebelde ante el orden religioso y familiar. Ambos personajes podrían ser leídos como portadores del gesto nuevo y profanador; sin embargo el narrador menesiano insiste en caracterizarlos, al primero, como un personaje engullido por su pose, que debe viajar a sus más recónditos "rincones interiores" para, desazonado, encontrar alguna huella de sí mismo, y al segundo, despectivamente, como "patiquín" y payaso que no soporta el enfrentamiento con la realidad. Más allá de importantes innovaciones temáticas - el adolescente al encuentro con lo perverso y la sexualidad, cierta insinuación del incesto o la presencia consistente en el cuento de mitos históricos librescos y cinematográficos-y formales - un vago carácter de montaje cinematográfico, la incorporación del monólogo narrado que se acerca en algunos momentos al monólogo interior, el fraseo breve, la definitiva interiorización del foco narrativo- la perspectiva dominante es crítica y moralista con respecto al personaje adolescente, en tanto insiste severamente en alertar sobre los peligros de la evasión y del gesto vacuo de ruptura. Este talante de vanguardia recatada y cauta podría igualmente reforzarse con algunas opiniones que expresara el propio Meneses por esos años. En 1934, en una entrevista hecha por su coetáneo Carlos Eduardo Frías, Meneses declararía esa específica y peculiar forma de vivir la vanguardia:

La crítica quizás debía preocuparse más que de separarse en "generaciones", de unir en tradición [subrayado mío]. Personalmente yo me siento más cercano a [Andrés] Bello que a Julián Padrón, representativo sin duda de la generación en donde me catalogan. ${ }^{9}$

La cita además de ilustrar la proposición anterior, permite acercarnos a uno de los meollos del carácter específico de ese proyecto vanguardista, nada ajeno al problema que en el ámbito latinoamericano ofrece la "incómoda" presencia de un escritor como Güiraldes en una revista de vanguardia o los textos iniciales de Asturias, Carpentier, de Andrade, los narradores del grupo Guayaquil, o el tránsito en Vallejo de Escalas melografiadas a El tungsteno. La oposición Andrés Bello/Julián Padrón resuelta en Meneses a favor del "viejo", revela otra oposición: la de cuando menos dos opciones de poética y de función intelectual presentes conflictivamente en la vanguardia latinoamericana: Andrés Bello, "fundador" del americanismo literario; Julián Padrón, narrador que, junto a Uslar Pietri, un año más tarde desde la páginas de El Ingenioso Hidalgo, fustigará las posiciones de los escritores "comprometidos", progresistas y nacionalistas, para defender la bandera del arte autónomo y del arte como suprarrealidad trascendente.

Meneses cerrará filas en torno a una idea de vanguardia marcadamente politizada vinculada a los movimientos e ideologías populistas de la época. Con ello retoma en parte la función característica del intelectual latinoamericano del siglo pasado: el del iluminado orientador y constructor de una nación, el del hacedor de un arte socialmente "útil y progresivo" - como quisieron Alberdi, Sarmiento, Lastarria o el mismo Bello. Dicha

\footnotetext{
${ }^{9}$ Luis Carlos Fajardo [seudónimo de C. E. Frías], “Guillermo Meneses, novelista inesperado", Elite, 474 (Caracas, 13 de octubre de 1934) 28-9 y 59-60.
} 
función que ligaba estrechamente el arte a la vida social y que habría sido reformulada por los criollistas del modernismo o por postmodernistas como Gallegos al adquirir una conciencia cada vez mayor de lo "propiamente artístico", será matizada ahora por una reforma de acentuada índole ideológico-política: la preocupación por los sectores populares. Como pocas veces antes el escritor querrá ser vocero - instructor- de esos sectores; en otras palabras, se instala en el discurso el talante populista nota dominante en la narrativa venezolana y latinoamericana de los años treinta.

Si la narrativa criollista del modernismo ilustró el fracaso del proyecto modernizador y civilizador del intelectual, hasta justificar en el caso de Urbaneja Achelpohl la necesidad del gendarme, la narrativa de Gallegos, en la coyuntura del tránsito del predominio del mundo rural al urbano, buscó en cambio conciliar el mundo de la tradición y la modernización a partir de una solución simbólica que tendría la idea del mestizaje como centro. E1 Meneses de los años treinta enmarcará su narratlva en una situación similar a la de su antecesor, aunque en ella hay dos cambios de foco significativos. Por un lado el viaje galleguiano hacia el espacio rural en trance de desaparición para aprender de él algunas claves de identidad, será reconducido en el narrar de Meneses hacia los espacios de las orillas de lo urbano: el puerto y el barrio marginal, bordes de la nueva cultura - por cierto, explorados ya, aunque tímidamente, desde el modernismo. Por otra, la representación de conjuntos simbólicos - las parejas concomitantes civilización/barbarie, rural/urbano, tradición/modernización - tendrá encarnadura particular, pues ahora el trauma del inevitable ingreso histórico a la modernización urbana se representará desde la perspectiva del personaje popular marginal representante de la nueva masa que ostentará la ciudad, individualidad desarraigada y desconcertada ante un proceso social que lo arranca de su centro originario para atraerlo y repelerlo. En vez de replantear el debate civilización/ barbarie se parte de la comprensión de que lo popular, más que una entelequia, una figura retórica, es el componente efectivo de la nacionalidad en crisis; por ello el escritor antes que un viaje espacial depositará su nuevo esfuerzo integrador en el "descenso" a las regiones cercanas de lo socialmente excluido. El marco y el descenso lo ilustra Meneses - forzando un tanto la lectura - en las primeras páginas de La balandra "Isabel" ..., cuando su cámara narrativa enfoca inicialmente el paso de la balandra junto a un trasatlántico alemán para instalarse al lado de una goleta un bole y una balandrilla, "sus compañeras" ( $D c$ 71); a continuación sigue el camino que conduce al marinero Segundo desde las calles encementadas del puerto a una "calleja empinada", "metida entre las casas severas, altas, mudas, de La Guaira vieja", hasta llegar al escenario central de la narración el botiquín; la trayectoria del personaje es casi una alegoría del viraje que ocurre en el proceso de la narrativa venezolana y en el intelectual que la produce:

Ahora, al doblar el recodo más oscuro [subrayado mío], en redor de la casa más severa, más muda y más alta, la calle cambia de carácter, se hace casi camino, y entra en el barrio pobre de las prostitutas $(D c 72-3)$.

Lo "más oscuro" será el nuevo espacio social a explorar: el botiquín irónicamente llamado "El Cuerno de la Abundancia"; el mar de la balandra también será "eso oscuro" $(D c 75)$, correlato simbólico de los personajes Segundo y la prostituta Esperanza, empujados sin gobierno de sí a la huida o la caída. 
El "otro" social será ahora sistemáticamente el nuevo protagonista de la narración. Julián Ponce y Rosa de la novela Canción de negros (1934; fechada en 1932), y Segundo y Esperanza de La balandra "Isabel" ... son figuras relativamente intercambiables. Julián Ponce carga con el estigma de un crimen pasional, su experiencia carcelaria y su deambular al encuentro con la ciudad son algunas diferencias con respecto a Segundo, simplemente marinero; pero a ambos los une la voluntad de calzar con la idea del macho, la búsqueda siempre insatisfecha de poder concentrada en la persecución del brillo del dinero o la posesión carnal de la hembra, y la errancia como sino. Rosa y Esperanza, son caras opuestas, virtud y vicio, pero ambas confluyen en la caída ante la ilusión amorosa. Todos ellos son personajes que intentan vivir mitos de cancionero. El personaje popular mientras asciende cae, pues se engaña y no es capaz de tomar conciencia del disfraz al que aspira. Macho y hembra populares coinciden en sus vivencias de deriva y fracaso y en su incapacidad para racionalizar. El escritor que observa la situación de la masa que accede al escenario urbano moderno construye esa imagen como explicación implícita y, aunque visiblemente distanciado y ajeno, intenta mostrar los resortes sociales, culturales y principalmente psicológicos del desarraigo y la caída.

Canción de negros y La balandra "Isabel" ... ofrecen diversos aspectos de interés. Además de los temas abordados - una sexualidad más abierta que en otros textos narrativos venezolanos de esos años, por ejemplo-, el trabajo sobre un nuevo tipo de protagonista narrativo - el popular, o mejor, el marginado social urbano- centrado en la construcción de su interioridad el carácter casi escénico de la narración, una escritura que busca el despojo y la condensación el trascurrir de la acción a base de retazos para producir un nuevo tipo de efecto realista (el arte es como la vida, fluida y caótica) y la notable disminución de la presencia autorial del narrador son aspectos que distancian de manera significativa la proposición menesiana de su tradición narrativa inmediata. Pero después de 1935, en cuentos como "Borrachera" o una novela como Campeones, si bien la innovación formal y temática se mantiene, la presencial autorial del narrador adquiere un espesor inconfundible. El escritor ya no se conforma con observar, mostrar y explicar; ahora además dado que sus personajes viven a partir de impulsos irracionales, querrá indicar el camino, orientar, instruir, acentuando en la narración su función pedagógica.

Días DE HIERRo NARRATIVO (1935-1939)

Este virtual "retroceso" es por lo demás común a buena parte de la narrativa de la época. Basta con echar un vistazo a novelas publicadas entre 1935 y 1940, cada vez menos salpicadas de innovaciones y más abiertamente politizadas como Fiebre de Otero Silva, Puros hombres de Antonio Arráiz, La carretera de Nelson Himiob o Mar de leva de José Fabbiani Ruiz, para dar de lleno con el realismo rosado: el regodeo en el feísmo para caracterizar el presente o el cierre narrativo de auroras multicolores anunciantes del futuro promisor, la abundancia de contrastes maniqueos, las cartillas democráticas y antitiránicas, que contrastan con exploraciones de textos anteriores de estos mismos autores - los relatos que Otero Silva publica en revistas, los poemarios Áspero y Parsimonia de Arráiz o Giros de mi hélice de Himiob. Como explicación de este retraimiento y radicalización en el caso de la narrativa venezolana, podría arguirse el auge internacional de los movimientos fascistas 
y antifascistas, el espíritu de reconstrucción nacional que sobrecoge a buena parte de los intèlectuales venezolanos tras la caída de la dictadura somecista y el paralelo endurecimiento, de las posiciones antagónicas nacionalistas/americanistas y artepuristas que hasta pocos años atrás habían permanecido represadas (ejemplos de ello serán la polémica sostenida entre los integrantes de la revista Arquero y los del Grupo Cero de Teoréticos alrededor de 1932, y más plenamente la ocurrida entre los de El Ingenioso Hidalgo y Gaceta de América en 1935). En Meneses, autor en el que con escasas interrupciones se verifica la idea de una doble vanguardia artística y política, pues participa activamente en la organización y dirección de diversas agrupaciones combativas de esa década, su narrativa se resiente también ese retraimiento en la exploración formal, aunque a decir verdad sus textos nunca llegan a abordar directamente el tema político.

"Borrachera" (1936), que integra Tres cuentos venezolanos, temáticamente se asimila a los textos precedentes de Meneses. Sin embargo el tratamiento difiere en forma sensible, no sólo porque el relato se construye a partir de contrastes gruesos, sino porque de la perspectiva de la narración emerge con fuerza con respecto al personaje marginal lo que hasta ahora tendía a disimularse o represarse: la figura del padre ductor. Aparentemente es el texto en el que más se profundiza el uso del monólogo narrado, pero el "desvarío" narrativo se justifica en términos realistas en tanto el cuerpo del relato es ocupado por el seguimiento de la borrachera de Antonio el "negro pobre"/"pobre negro" - antes y después de. Antonio es hijo del éxodo que lo ha llevado del campo a la ciudad. La narración lo encuentra una noche cualquiera en un botiquín de barrio entregado al berro. El vértigo alcohólico lo sume en el deseo de mujer e inconscientemente le recuerda una canción que le cantaba su madre lavandera en el idílico espacio original. El encuentro con una prostituta propicia la fusión de deseo carnal y regreso al vientre, de madre y prostituta. La mañana le permite reconocer el entorno - el sexo feo de la prostituta, su cuerpo magro y ruinoso, el cuarto grasiento y grotesco- y reconocerse en su descenso al infierno. El recuerdo de que debe ir a trabajar lo revive y el aire de la mañana lo consuela "despacio, como si tuviera en su sustancia las manos cariñosas de la madre - negra Jacinta - que ahora, estará lavando en la quebrada rabiosa y pura de la hacienda lejana" ( $D c$ 109). He ahí el camino. Esta proposición de simbólica vuelta por vía del trabajo virtuoso a la madre/tierra se repetirá de algún modo en su siguiente novela, Campeones.

De apariencia semejante a la coetánea novela Capitanes de la arena, de Jorge Amado, Campeones narra la historia de adolescentes marginales de los alrededores del puerto de La Guaira en busca de ascenso social fácil y rápido por la vía del deporte. La pureza de la vida en el mar - variante del campo-y la infancia son prontamente contaminadas por el despertar de la sexualidad y el contacto con los valores del mundo urbano: éxito y poder, dinero y mujeres, vistos como degradados, como disfraces deshumanizados. Uno de ellos morirá; dos de ellos triunfarán pero sólo efímeramente: Ramón Camacho, boxeador, terminará siendo presa de su apoderado, y Teodoro Guillén, pítcher estrella embriagado por el fulgor del éxito, se verá reducido al papel de coime de botiquín y cerrará la novela disfrazado grotescamente de mujer. El único que trata de hacerse una vida a fuerza de labores honradas, será Luciano Guánchez quien, a pesar de sentir envidias y dudas ante los triunfos de sus compañeros, tras recapacitar y aceptar el buen camino del trabajo (uno de sus proyectos será montar una frutería, como para no perder el contacto con lo natural) y 
del amor "de mil lazos de sencillo erotismo vital" de Pura Guillén, será bautizado por su amada - y el narrador - "Campeón mío de todos los días". ${ }^{10}$ El encauzamiento monológico es expreso. La posibilidad de integración del marginal a la nueva sociedad, a un posible nuevo proyecto de nación, pasa por el sendero que evita la caída en los falsos valores del espacio urbano moderno y que reconquista los perdidos: madre, tierra, amistad solidaria; ese sendero, forjado a golpe de constancia y voluntad, lo conducirá a la meta de una decente clase media - por ejemplo, la del pequeño comerciante. El específico tipo de populismo nacionalista de este Meneses muestra sus limitaciones y su trasfondo en tanto promueve los valores del mundo que aparentemente cuestiona. La distancia del escritor de su objeto narrativo predilecto, el otro social, y su paternalismo se harán patentes como nunca en esta novela cuando el narrador llegue incluso a perder la compostura ante la indolencia y las dudas que por momentos atraviesan a su protagonista: lo deja hablar, simula escucharlo, lo contradice, lo corrige y lo regaña como a un niño:

Eso piensa Luciano. Ideas que no son, ciertamente, de luchador sino de tranquilón que espera serenamente la rendija por la cual se meterá en la casa del triunfo ... Luciano es así: jugador esperanzado de la ruleta del mundo, que espera el momento de la suerte para dar su zarpazo; el no arremete para vencer, sino espera que la vida le regale toda la realidad de su callada ambición ...

Como siempre, cada mañana hace su tarea: $y$, cuando lo aplasta el peso de su esclavitud dice su cantilena que quiere ser rebelde pero que apenas es ingenua algún día ... ( $C n$ 155).

Poco después este primer Meneses, agotado de su relación trabajosa con el otro, dará con un personaje que sí calzará los puntos del símbolo de su proyecto nacionalista. No será ya un marginado ni social ni étnicamente, sino la vuelta a la entelequia que habría descubierto Gallegos en los años veinte en La trepadora y Doña Bárbara y que profundizará en sus novelas de los treinta hasta llegar a la Remota Montiel de Sobre la misma tierra: el mestizo, en la siguiente novela de Meneses llamado José Vargas, que por añadidura como para facilitar o acentuar la identificación de la voz narrativa con el protagonista, es un poeta.

DESCUBRIMIENTO DE LA INTRAHISTORIA Y DISEÑO DEL MITO (1942)

Entre 1939 y 1942, tras el fracaso de la conformación de bloques políticos progresistas y algunas desaveniencias no claramente establecidas, Meneses se retira momentáneamente del juego político y de Caracas. En 1942 retoma esa actividad apoyando abiertamente el proyecto populista de Medina Angarita y desarrolla una intensa labor periodística. Para esa fecha ya habría publicado su tercera novela. Junto a La balandra "Isabel" ... y "Adolescencia", El mestizo José Vargas es de los textos del primer Meneses que mayor interés puede despertar en el lector de hoy. La novela se dispone, aún más que Campeones, como una novela de aprendizaje. José Vargas escuchará historias, conocerá gentes y modos de vida y nacerá al mundo con una respuesta abierta a la utopía.

${ }^{10}$ Guillermo Meneses, Cinco novelas (Caracas: Monte Ávila, 1972) 238. En adelante cualquier cita que se haga de esta edición se limitará a indicar las siglas del título y la página. 
La "Prímera Jornada" de El mestizo ... se inicia con una oposición que ha ido insinuándose en textos anteriores: el mundo natural primigenio, inocente y mítico vs. el mundo humano del pasado y el presente figurado y sustentado por la "voz de los ancianos": en otras palabras la imagen de la historia como caída:

Pero existe la voz de los ancianos, su voz, con peso y valor de semilla. Existe la memoria, la experiencia, el recuerdo. La voz de los ancianos se acerca a nosotros y crea en nuestra mente otra tierra oscura - tierra del pasado - que lucha con la tierra verdadera, que toma disfraz de tierra verdadera, porque quiere ser más eficaz y real que la tierra donde nacimos (Cn 241).

La voz de los ancianos, el disfraz, será la representación de lo viejo y de lo que en la historia e incluso en el presente ha sido imagen predominante. Ella introducirá el primer conocimiento del mundo de José Vargas, personaje aspirante a la condición de mito novelesco - a la vez retrato de joven artista y símbolo de la nueva nacionalidad- el mestizo; "De la tierra surgen los sueños que lo hacen dios; del oscuro fondo del pasado viene la memoria que lo hace hijo de la carne. Luchan en él dos mundos" (Cn 242). El eje divino/humano, complementario de la oposición naturaleza/historia, se completará con otras oposiciones, si cabe, aun más significativas: además de dualidades frecuentes en el texto como luz/sombra, pureza/vicio, quiero destacar las que establecen contrastes entre las presencias o formas interiores y las realidades objetivas, lo viejo y lo nuevo, y "la voz de los ancianos" y la voz "de los que no tienen nombre", pues serán la base de la proposición novelesca.

Si algo quiere privilegiar esta lectura de la novela es el intento de definición de lo que es el hombre y el espacio social y cultural venezolano en su doble versión: visible e invisible (el sabor a Mallea es premeditado). La forma del Bildungsroman propiciará la formación de ese tramado. El poeta José Vargas en su contacto con el mundo irá deshojando la margarita de las realidades con las que armará su bagaje su sensibilidad, oscilando entre cielo y tierra, le permitirá descubrir en cada palabra, gesto, elemento, o relación, lo que en ellas hay de disfraz y de verdad -esta última de índole casi siempre oculta e interior. El mundo novelesco se ofrece ante el protagonista - y el lector-como un cruce de caminos: en una primera instancia dado en la pareja espacial Ciudad Vieja - presidida por el orden impuesto por la figura paterna, Aquiles Vargas, heredero en decadencia de la figura del caudillo-y Santocristo - espacio materno de Cruz Guaregua, ubicado sintomáticamente a la orilla del mar-ambos espacios sin referente geográfico real, encarnan como realidades las fuerzas internas y subterráneas de la historia la "voz de los ancianos" y la de los que "no tienen nombre"; a su vez ambos conforman la historia y lo viejo en un espacio que ya recibe signos patentes de un orden nuevo el de Caracas ciudad a la que se dirigirá José Vargas al finalizar la novela.

Pero ¿qué conoce y que aprende José Vargas? ¿Qué constituye la forja de su "moneda propia"? Para sintetizar diría que el poeta Vargas reconoce que su reino no es de ese mundo, en tanto su ámbito de origen se ha distanciado de lo natural y la pureza: Ciudad Vieja, dominio de Aquiles Vargas, sin duda objeto del mayor grado de descalificación narrativa, es un mundo excesivamente mixto, pervertido, degradado, en el que no tienen cabida las hazañas justicieras de ancestros como Diego Vargas; Santocristo, el espacio de 
los pescadores - algunos de ellos sus hermanos maternos- se ha ido contaminando de la decadencia y degradación propias de los valores caudillescos de Aquiles.

La novela tiene como eje el proceso interior que ocurre en el protagonista a partir de su contacto con el mundo y se diseña en torno a la idea de las sucesivas fascinaciones y los inmediatos desencantos de José Vargas en cuanto se pruduce su mise en réalité. El discurso novelesco presenta diversos espacios/personajes, portadores cada uno, casi de un modo simbólico, de una posibilidad social o cultural. Además de las grandes parejas de la novela -Aquiles Vargas/Ciudad Vieja/voz de los ancianos y Cruz Guaregua/Santocristo/voz de los que no tienen nombre- la narración introduce otros elementos que no sólo dan profundidad y espesor novelescos a $E l$ mestizo ... sino que contribuyen a dar forma a la opción final del protagonista. Así, la fígura de Aquiles Vargas es completada por el representante de la oficialidad de Ciudad Vieja, el bachiller Temístocles González, juez del lugar de quien llega a ser secretario José Vargas. Por él conoce no sólo la crudeza de la violencia y el crimen que prevalecen en ese mundo sino las "asqueantes fuerzas" el "vicio baboso" (279), lo abyecto de lo humano. El bachiller González, que satisface su voyeurismo entregando a su esposa a la "indefensión" de sus jóvenes empleados aparte de ser una de las vías que encuentra José Vargas para conocer otras caras de la realidad -el mundo de la perversión por ejemplo- es el medio por el cual el poeta conoce la pasión carnal, al no poder evitar el desarrollo del deseo voluptuoso por Goyita, la esposa del juez. Ella, de extracción popular, perteneciente por tanto originalmente a "la vida innumerable del pueblo, de los que no tienen nombre", será descartada por el protagonista al comprobar que ha sido demasiado moldeada por el mundo del bachiller. Mister White, pastor evangelista, puritano permenentemente atónito ante las extrañas costumbres de los lugareños, dados - según él- al ocio y la concupiscencia, es sutilmente ironizado y ridiculizado por la narración al marcar con insistencia su ser ajeno, la incomprensión de la mirada del yanqui misionero.

En otro sentido, si bien los sucesivos descartes del mundo del orden que es Ciudad Vieja impelen a José Vargas a buscar el lado oscuro de su origen, al otro social ligado a él por lazos de sangre, gracias al cual descubre lo puro y luminoso del ámbito inserto en lo natural —el mar, descubre también finalmente que la luz tiene su sombra, que ese "pueblo", en principio transparente, ha adquirido en su histórica sujeción al mundo de los Vargas, sus valores pervertidos y degradados. Así, ve en Chuito rasgos que son reminiscencias del espacio paterno, y Cruz, por las condiciones de su vida, no puede ser la madre que José espera, el refugio sentimental. La imagen del bobo del pueblo remata algo grotescamente su desprendimiento del mundo - materno y acuático- de Santocristo.

Es así como José Vargas debe partir y negar la experiencia concreta de los ámbitos de Ciudad Vieja -indeseable - y Santocristo - ajena. Caracas, el nuevo mundo urbano será la alternativa. La historia novelesca es rescatada por el protagonista como aprendizaje interior y sólo en esa interioridad adquiere forma peculiar y sentido. Es la sensibilidad del poeta la que finalmente vislumbra la existencia de fuerzas intrahistóricas que ordenan el mundo y que en su revelación casi epifánica propician la toma de opción, la búsqueda de la "moneda propia"; búsqueda que se activa por la medalla que le entrega la (sintomáticamente) negra y joven (pura por ende) Georgina. De su peripecia queda aquello que lo acerca a la pureza; el cariño y el cuidado, los gestos de mujeres como su tía Emilia 
y las negras Belén y Georgina, la resonancia de figuras legendarias y justicieras como Diego Vargas: todos ellos tienen en común el nulo poder que ejercen en el orden viejo. Queda la certeza de que las fuerzas constructivas sobre las que debe erigirse la utopía futura, la nueva nación deben tomar asiento como lo ilustran con insistencia las últimas páginas de la novela en "la vida innumerable del pueblo". Ese "pueblo", como se vio, no tiene otra forma de concreción más que en el futuro, en tanto pasado y presente no pueden ser asumidos con plenitud, y sólo pueden ser aprehendidos por medio de una operación simbólica interior: la que en última instancia produce la escritura. Marcha así José Vargas hecho de la doble materia del sueño —que lo conduce de madrugada al despuntar el alba (no podía ser de otra manera), a Caracas-y de la historia - descartable como experiencia vital específica pero exaltable en tanto una zona de ella ha sido mitificada:

A esas presencias innumerables unidas en una sola vida plural y eterna, estaba amarrada el alma de José Ramón. No a éste o aquél cariño, sino a la fuerza torrencial, ... pura como el viento y la playa, pura como el vuelo y como la mano que siempbra y trabaja, a la fuerza pura y eterna de la mujer ..., del hombre que nadie recuerda. Las innumerables presencias humanas que de la tierra surgían, formaban una sola voz que si brotaba de aquella sombra también salía del alma de José Ramón ( $C n$ 364).

Marcha a Caracas el poeta, convertido él también en figura mítica volcada al futuro: "es una flecha lanzada por el centauro - hombre puro, bestia pura - cuya fuerza es la voz y la vida de las gentes que no tienen nombre" ( $C n 365)$. Con ello el proyecto narrativo de este Meneses pretende salvar tanto su dificultad para insertarse en cualquier porción concreta de la realidad histórica o social - dominante o dominada - como la actitud contradictoria ante sus protagonistas del pasado, al fiar ahora la rienda del proyecto a la figura de este mestizo - como lo hará el Gallegos de Cantaclaro, Canaima y Sobre la misma tierraespecie de "sí mismo" que ha descartado caudillismos, brillos de éxito y poder y marginados reales, para entregarse a un sueño utopista, urbano, populista y conciliador.

VALOR Y CIFRA DE LA DUDA (1946-1962)

Las modificaciones que he tratado de mostrar en el proyecto narrativo del primer Meneses son, si se quiere, internas y, aunque importantes, no afectan sustancialmente su diseño global. Pero el golpe de timón que se produce en Meneses en lo escrito desde 1946 es drástico como si el autor se hubiera mirado en un espejo y se hubiera dicho: "de hoy en adelante voy a ser otro; entierro al Meneses que fui" - io: "voy a quitarme el disfraz y me dedicaré a ser el que en el fondo siempre quise ser"? Especulaciones al margen, el cambio se produce de manera ostensible. Cambian el tipo de protagonista las estrategias narrativas, los temas y soluciones, el proyecto narrativo en su conjunto. No se trata de uno de esos cambios tan usuales en nuestras diversas vanguardias - modernismo, vanguardia histórica, años sesenta, momentos en los que la imagen inicial que desarrollan los escritores disidentes durante los primeros tiempos de la emergencia suele dispararse hacia el lugar menos pensado una vez logrado el objetivo de abordar el espacio cultural. Se trata de un viraje que ocurre cuando Meneses es escritor desde quince años atrás, goza de popularidad y tiene en su haber tres novelas y dos volúmenes de cuentos, además de una cantidad incontable de 
artículos para periódicos y revristas. Una parte apreciable de la crítica sobre el escritor lo ha reconocido así. ${ }^{11}$

No creo que necesariamente los cambios en un escritor deban ser, además de descritos, explicados o deban tener alguna explicación, pero aquí intentaré hacerlo. Podría decirse cautelosamente y con diversos grados de razón que el viraje de Meneses obedece a un cambio motivado por elementos no exógenos sino inherentes a su proceso reflexivo-artístico, cuya resultante sería la verificación del agotamiento de una propuesta narrativa - la vinculada simultáneamente a la tradición criollista y la vanguardia - y la consecuente reconducción del empeño escritural hacia otro modelo artístico con el que Meneses estuvo en contacto por vía de lecturas directas o indirectas desde los mismos días iniciales de la vanguardia -Dostoievski, Proust, Mann, Joyce, y luego Malraux o Sartre. Podría incluso - además o en vez de - articularse dicho cambio a las notables transformaciones que en el sistema literario y cultural venezolano y latinoamericano se producen en esos años cuarenta. La década marca el inicio de la decadencia del realismo rosado y la metamorfosis sustancial de las estéticas regionalistas: el realismo mágico o maravilloso que toman forma definitiva con Carpentier, Asturias, Arguedas, Rulfo o Guimarães Rosa y poco después con García Márquez; el realismo fantástico que gana adeptos señeros encabezados por la veta severa de Borges y Bioy Casares o la más irreverente de Arreola, Cortázar, Monterroso; o propuestas como las de Sábato, Marechal, Onetti, Revueltas ..., hablan por sí solas de la magnitud del cambio de dominante en el sistema narrativo - asimilable al que sufren otros discursos literarios y culturales concomitantes. En Venezuela ocurría algo parecido. Los escritores, en su mayoría cuentistas, que se inician durante los años cuarenta - Gustavo Díaz Solís, Antonio Márquez Salas, Oswaldo Trejo, Alfredo Armas Alfonzo, Andrés Marino Palacio- nucleados algunos de ellos en torno a la revista Contrapunto, decretarán el comienzo del fin de la era galleguiana reforzaran el estudio de otro tipo de autores europeos y norteamericanos - Mann, Huxley (obviamente), Sartre, Céline, Heidegger, Dos Passos, Faulkner-y asumirán la bandera del universalismo como principio básico de la orientación artística, incluso en los casos que no descarten la inserción del trabajo artístico en un espacio que podría considerarse nacional o local. Podría ser esto suficiente como "explicación" descriptiva, pero quiero añadir algo más; la idea de que el cambio de orientación estética es motivado en el caso de Meneses por el desencanto político, por la conmoción que ocurre en el escritor tras la caída abrupta del proyecto de Medina Angarita el 18 de octubre de 1945, proyecto que Meneses, como muchos intelectuales de la época (Antonio Arráiz, Mariano Picón Salas, Miguel Otero Silva, Fernando Paz Castillo, Luis Barrios Cruz, Carlos Eduardo Frías, Juan Liscano, Carlos Augusto León, Antonia Palacios, Aquiles Nazoa), suscribió y defendió abiertamente por entender que en ese proyecto encarnaba la posibilidad de realización de los valores - liberales, burgueses, democráticos y nacionalistas- de la vanguardia del año 28. En un artículo del 16 de octubre de 1944

1 Confróntese cuando menos: Laura Corbalán, "Guillermo Meneses, lo otro como doble" Hispamérica 31 (1982) 79-84; Juan Liscano, Panorama de la literatura venezolana actual (Caracas: Publicaciones Españolas, 1973) 84-92; Arlette Machado, Asedio a Guillermo Meneses (Caracas: Monte Ávila, 1982); y Alicia Segal, “Guillermo Meneses, novelista del azar”, prólogo a Cinco novelas, 9-17. 
("Respaldo a la política del gobierno", El Nacional 7) se expresará Meneses en los siguientes términos:
El gobierno de Medina se ha caracterizado por un a visión moderna, consciente, eficaz, de los problemas venezolanos y por la decisión de solucionar esos problemas en sentido defensivo de los intereses populares, sin culpables condescendencias para las ambiciones de determinado grupo social. El gobierno del general Medina ha marcado indiscutibles avances de justicia social, decencia política y capacidad admninistrativa.
Los intelectuales y artistas venezolanos, así como los que formaron la altiva generación del 28, están con el gobierno del general Medina, porque ha realizado múltiples ideales con los que soñaron siempre los hombres más representativos de Venezuela.

Desde luego la esfera de lo político y lo literario - sobre todo en estos momentos de la historia (el de Meneses y el mío)- son diferentes, pero lo menos que puedo hacer es señalar la coincidencia temporal del desencanto político y el viraje de orientación artística en su narrativa - lo mismo diría que ocurre a partir de 1945 con otros narradores venezolanos como Antonio Arráiz, Nelson Himiob, José Fabbiani Ruiz o Felipe Massiani- que lo llevará a convertirse en el paradigma de posteriores promociones de escritores.

El desencanto político de Meneses puede verificarse por medio de diversos testimonios y documentos. En la biografía Asedio a Guillermo Meneses, Arlette Machado recoge en tres frases la actitud del escritor ante la caída del proyecto nacionalista de Medina en 1945: "Primera gran amargura ... Destierro voluntario ... Desilusión del país político". La que fue por entonces su esposa, Sofía Imber, cuenta que el hecho "lo afectó de tal manera que quiso irse de Venezuela". Alfredo Armas Alfonzo, joven narrador de aquella época, afirmaría hace algunos años que el derrocamiento de Medina "pareció lastimar una llaga de la que Meneses nunca se curó". ${ }^{12}$ De hecho en 1946 Meneses se autoexilia y marcha a Bogotá. Desde entonces su participación en la prensa será cada vez más escasa y exhibirá otro tono; nunca retornará a la actividad política e incluso durante la dictadura perezjimenista trabajará como empleado de la Embajada en Francia. Por otra parte, si hasta los años 44 y 45 es posible encontrar en la prensa artículos de Meneses de un optimismo y una organicidad militante inocultables, desde 1946 los artículos que envía desde Bogotá o los que publica de regreso a Caracas traslucen no sólo una actitud distinta sino que parecen exhibir valores y fórmulas que nutrirán paralelamente el cambio de su narrativa. Así, en un artículo de 1946, "En estos días" (El Nacional, 22-5-46), además de definir el nuevo tiempo como "amarga época", señala ideas como las siguientes: "parece que, cada día más, los conceptos más contradictorios estuvieran unidos y se dividieran en pareceres contrapuestos los pensamientos que, hasta hace poco, se creyeron semejantes"; o "Por América, hasta la palabra revolución sirve de lujoso antifaz para las dictaduras" (el golpe del 18 de octubre de 1945 fue designado por sus actores como "Revolución de Octubre"). Poco después, en 1948, publica un artículo en el que - tras la caída ahora de Gallegos- concibe esos años como los de la entronización de la "mentira" en la realidad histórico-política reciente y cuestiona el uso y valor demagógicos de la palabra ("El valor de las palabras", El Nacional,

${ }^{12}$ A. Machado, 72. Alfredo Armas Alfonzo, "Oyendo a Meneses", El Nacional (23 de abril de 1983) A-4. 
1-11-48). ¿Cómo pasar por alto esta obvia relación si, por ejemplo, el relato "La mano junto al muro" y la novela El falso cuaderno de Narciso Espejo, se montan sobre la idea de la inútil diferencia incluso de lo que parece opuesto? ¿Cómo olvidarla si uno de los núcleos centrales de la narrativa de Meneses posterior a 1946 será la reflexión sobre la capacidad de la palabra artística para dar cuenta del mundo histórico, relación fundamentalmente opaca y tensa al mísmo tiempo verdadera y falsa?

Esta segunda etapa de su narrativa será definida por el propio escritor como la del predominio de los "valores de la duda", la "inseguridad del propio testimonio" y "lo que puede reducirse a las contraposiciones entre el disfraz y el espejo" ( $D c 43)$. Duda ante el testimonio, espejo y disfraz, son ciertamente líneas determinantes del nuevo proyecto narrativo de Meneses. La duda se dirigirá hacia dos direcciones que abarcan poco menos que todo el mundo y la escritura. El espejo y el disfraz constituirán los símbolos básicos de esta otra etapa narrativa. Ambos elementos estaban presentes en lo escrito anteriormente, pero aquí la función y el sentido son otros. El espejo era el objeto físico que le permitía al narrador mostrar el rostro grotesco y degradado de ciertos personajes (el Julio Folgar de "Adolescencia" o el Ramón Camacho de Campeones); el disfraz, la marca que designaba el ingreso en el mundo de los falsos valores (Julio Folgar caracterizado como "Pierrot adolescente" o Teodoro Guillén disfrazado de mujer). Ahora el espejo será un espacio de otra índole - incluso cuando haga su aparición como objeto físico en los textos-pues pasará a convertirse en símbolo metafórico de la escritura: el lugar del registro del mundo que sólo es capaz de producir sombras, imágenes equívocas, misterios sin respuesta; el disfraz dejará de ser vestidura propia de personajes degradados para convertirse en uniforme de todos y de todo - escritura incluida - en principio que identifica a lo existente en cualquiera de sus formas. El cotejo del antes y el después da pie a introducir lo que me parece un rasgo característico de las estrategias discursivas desplegadas por Meneses después de 1946: la inversión paródica. La mujer, el as de oros y la luna (1948), "La mano junto al muro" (1952), El falso cuaderno de Narciso Espejo (1953) o La misa de Arlequín (1962) son textos que pueden ser leídos como visitas escriturales a temas ya frecuentados por el escritor —el adolescente y el marginal, sobre todo — para replantearlos y modificarlos en términos radicales. Trataré de describir sintéticamente los cambios que produce la inversión paródica en la configuración del mundo narrativo y en la concepción misma del hecho artístico.

La escritura muestra su laboratorio y apunta con mayor o menor evidencia los motivos de esa metamorfosis. La fuente a partir de la que se articulan otros elementos modificados es la idea del desencanto del fracaso. Los textos del primer Meneses construían un diagnóstico de los males de la realidad nacional; en ese marco diseñaba personajes en crisis y señalaba rumbos - la necesidad de la búsqueda de otra forma de ser en el mundo y de otro mundo - asentaba la posibilidad del sueño en la realidad - las auroras. El empeño de la escritura era el relevamiento de esa imagen; el intelectual narrador desde su altura se entregaba confiado a prescribir fijando identidades posibles, sea para los nuevos sectores populares urbanos, sea para el propio intelectual. Esas identidades posibles, conclusiones de cuentos y novelas anteriores, se decretarán en bancarrota y se verán reducidas a la ostentación amarga del disfraz y la mueca. 
Esta negación del principio de identidad se revela en dos instancias distintas. Por un lado, en lo que respecta a la ejecución de la voz narrativa, es posible observar un hecho inédito en Meneses: la abrumadora presencia de narradores integrados a la historia, sea en funciones protagónicas - confesionales casi siempre - o de engañoso testigo. Desde el concurso de esta subjetividad, parcialidad fragmentada, el mundo narrativo adquirirá su inestable y horrosa configuración: lugar de lo abyecto en "El duque", círculo inútil en "Tardió regreso a través del espejo", vertiginoso caos en "La mano junto al muro", absurda nube amarilla o noche envolvente en El falso cuaderno ..., espacio agónico y farsa teatral en La misa de Arlequin. Los personajes narradores blanden - a veces, como en "Un destino cumplido", vociferan - las consignas del fracaso, la melancolía o la muerte, y en ello encuentran delectación y regodeo. La idea recurrente del fracaso completa figuradamente la trayectoria vital de los adolescentes del primer Meneses al encarnar ahora en cuarentones desencantados siempre al borde del suicidio, que confiesan la cancelación del sueño - Federico Montesdeoca, Juan Ruiz - o la inutilidad del éxito (otra forma de derrota) - José Prados, Narciso Espejo. La relación estrecha que se establecía entre el sueño del futuro y la identidad ideal, en su caída, tiene como efecto aquí la producción de una galería de personajes que son un conjunto vacío de disfraces. No deja de ser sintomático a este respecto la recurrencia al apodo - lo que es decir a la máscara. El duque, Bull Shit, Dutch, Narciso Espejo, Arlequín, son entelequias vivas y en nada se diferencian de los nombres convencionales. El autor de la prostituta de "La mano junto al muro", colega del personaje de La balandra "Isabel" ..., parece decirle a Esperanza: "Tu nombre real es Bull Shit". Los personajes cambian sus nombres de pila o no los tienen, asumen la máscara como verdad, se desdoblan en el gesto: lo otro vacío del disfraz es su identidad. Los desdoblamientos se suceden de texto en texto, todo tiene dos caras: Federico Montesdeoca (el que soñó) se convierte en El Duque; José Prados (poeta y comerciante hastiado de ambos ejercicios) se ve reproducido en Raúl Kaufmann; Juan Ruiz (el fracasado suicida) asume la identidad de Narciso Espejo en la escritura y José Martínez la de Arlequín; en "La mano junto al muro" el proceso de desdoblamientos es llevado hasta el vértigo y enlaza a todo lo existente.

Dos casos ejemplarizantes de esta negación del principio de identidad y de la posibilidad del sueño son "La mano junto al muro" y El falso cuaderno ... En la novela El falso cuaderno de Narciso Espejo el tema central es la inutilidad de la diferencia, en la primera parte de la novela, Juan Ruiz confiesa inicialmente su fracaso y opta por presentar la autobiografía apócrifa —es decir, el diseño de la identidad - de Narciso Espejo, adoptando para ello su voz. Esa voz narrativa impostada insiste en marcar el carácter de invención, modificación o deformación y al mismo tiempo de testimonio de cuanto ha escrito sobre sí mismo: la falsedad del testimonio o la verdad que hay tras la impostura y la invención. La segunda parte de la novela se organiza como respuesta judicial al "crimen" cometido por Juan Ruiz al asumir la identidad de Narciso. Como defensor de sí mismo, Narciso Espejo recurre a diversos testigos. La empresa se revela como inútil pues, por un lado, se asienta sobre la demostración de algo que Juan Ruiz o el Narciso literario nunca negaron la falsedad del cuaderno, y, por otro, porque al revisar el cuaderno no hace más que confirmar lo que éste tiene de testimonial. Al verse reflejado en el espejo de lo literario e intentar corregir la imagen sólo logra reforzar la ambigüedad del reflejo, entre otras cosas porque sus 
instrumentos entre otras cosas porque sus instrumentos son también, como en el caso de Juan Ruiz, la palabra y la memoria. Para descalificar a Juan Ruiz y preservar su identidad reconstruye las condiciones de escritura del cuaderno: la extraña presencia omnímoda de la nube amarilla sobre la ciudad; la melancólica nostalgia que produce la visión de Lola "la luminosa" - imagen del amor soñado - convertida en el presente en patética ruina física; o el fracaso vital de Juan Ruiz, arcipreste en negativo - siempre reconocido por el acusado. En auxilio de Narciso trabajan Pérez Ponte y José Vargas, el mismo protagonista de la novela del 42, ya instalado en Caracas. José Vargas es Jefe de Redacción de un diario y su labor es descrita como la del inflador de noticias ( $C n$ 443). Por lo demás, Vargas, en un momento determinado de su relación, reproduce un diálogo con Juan Ruiz para confesarse y completar el final del 42: "Nada me lleva a ninguna parte, Juan Ruiz. Apenas si soy un traidor. He traicionado. La madrugada lo sabe. Me ha excluido" $(C n 463)$. El reino de la respuesta, de la presunta verdad, es también, como la ficción de Juan Ruiz, la mentira y el fracaso. Una última vuelta de tuerca que ofrece la novela, como para ratificar la prevalecencia de lo ambiguo y dudoso, del misterio y de la ausencia del sueño y la identidad ocurre cuando el Narciso real revela que su nombre es una máscara, que no es la diferencia y que lo descrito por Juan en su cuaderno es sólo sueño ingenuo de una historia apenas posible:

\begin{abstract}
Para terminar, insisto en afirmar que yo no soy Narciso Espejo. Me llamo Pedro Pérez$\mathrm{u}$ otro nombre sin especial distinción - y soy un hombre - uno como tantos- que escucha sus propios pasos en elsilencio de las calles nocturnas y piensa en la angustia del compañero desaparecido ( $\mathrm{Cn} 474$; así en original).
\end{abstract}

Las últimas frases de la novela unen dos palabras claves "nombre", "hombre"; ambas designan referentes indiferenciados. Apenas pervive el "silencio" o la "angustia". La presencia del doble, de la imagen y el objeto, la apariencia de lo diferente y opuesto, sólo sirven para acentuar en el contraste la ausencia de "distinción": lo/el otro no existen.

El desdoblamiento de identidades se lleva al paroxismo en el relato "La mano junto al muro". Escrito en 1951 y ganador en el 52 del premio de cuentos más importantes de la época -el de El Nacional - este relato se ha convertido en emblema de modernidad para la mayoría de los narradores de décadas posteriores. Allí todo es apariencia engañosa, todo se funde en el caos del vacío; el ritmo y la estructura de la narración, similar a los del Bolero de Ravel o La celosía de Robbe-Grillet, conducen a la exasperación de lo real representado, a su desrealización extrema. En ese particular cosmos se funden vida y muerte, mano y muro, aquí y adiós; el ahora es también antes y después, la prostituta es cualquiera de las prostitutas o una virgen flamenca; y el narrador puede ser detective, marinero, criminal. Organizado engañosamente como un relato policial en el que se intenta reconstruir el asesinato de Bull Shit, el relato consagra el enigma irresoluto, el círculo de la nada. El carácter de reflexión ontológica se hace obvio en un pasaje de resonancias bíblicas -Eclesiastés:

Lo que podría separar una cosa de otra en el mundo del tiempo sería, apenas una delgada lámina de humana intención, matiz que el hombre inventa; porque, al fin, lo que ha de morir es todo uno y sólo se diferencia de lo eterno ( $D c$ 209). 
El narrador/detective pretende desviar la atención del lector sobre la posibible presencia de dos o tres marineros y de otros sospechosos. Pero una minuciosa pesquisa de lectura revela que los marineros pueden reducirse a uno, que éste puede confundirse con otros sospechosos - Dutch - que puede ser el mismo detective narrador y que incluso todo puede surgir, en última instancia, del espejo del discurso - de la escritura. La identidad se desvanece, hecho que se refuerza cuando a mitad del relato se incorpora la frase carrolesca "A través del espejo" y lo imaginario o lo esquivo toman consistencia absoluta. Después de todo, lo narrado se registra en un espejo que pendía de "una larga cuerda enredada en un clavo que, a su vez, estaba hundido en la madera del pilar que sostenía el techo", por ello "temblaba por los movimientos del cuarto, por el paso del aire, por todo" (Dc 217).

Evidentemente se trata de un proyecto narrativo radicalmente otro. Para confirmarlo, a lo descrito habría que añadir la frecuente parodia de géneros y fórmulas tradicionalmente consideradas realistas, la recurrencia a la intertextualidad paródica y las citas especialmente establecidas a partir de textos y figuras clásicos, de clásicos contemporáneos (Carroll, Joyce, James) y de su propia narrativa - la sistemática ironía sarcástica, la dimensión autorreflexiva y metaficcional de textos como "Tardío regreso a través del espejo", "La mano junto al muro" y las novelas El falso cuaderno ... y La misa de Arlequín (ese tipo de discurso que, según aquella gastada retórica de los setenta y ochenta, muestra su productividad, se construye y desconstruye sin cesar). Temáticamente todo apunta al desencanto. Los adolescentes adultos se solazan en sus ruinas - vacío interior, andrajos, máscaras; los marginados sociales son ahora marginados existenciales. La prostituta Bull Shit no enrostra su nombre contra un patiquín, sino que es metáfora del mundo. Puede, incluso, verificarse la presencia de otros personajes "populares", pero con una función muy distinta. Por El falso cuaderno el lector de Meneses se entera mediante una referencia muy pasajera de que Luciano Guánchez, el protagonista de Campeones, unió su nombre al de los muertos por una epidemia; el protagonista de "Alias, el rey" —cuento recogido en La mujer, el as de oros y la luna - acaso el único relato de esta etapa que tiene en ese papel a un personaje popular, narra la conversión de un adolescente de barrio en ladrón y su inevitable caída tras un ingenuo momento de fulgor y éxito; caída y derrota, la ausencia de salidas, también es el fin inevitable de los personajes de extracción popular que integran La misa de Arlequín.

La lectura de este desencanto como núcleo de este proyecto narrativo y del viraje estético como efecto no sólo del desgaste de un código o de la imposíción de otros, sino del fracaso de un proyecto político populista y nacionalista, quedaría un tanto en el aire si obvio un hecho, registrado temáticamente en sus últimas novelas, que me parece cuando menos significativo y es el indicio más claro para permitir, a partir de los textos narrativos mismos, leer el desencanto menesiano como algo más —o menos- que desgarrón existencial o cansancio artístico. Arriba, cuando pasaba revista a los años treinta, los del hierro narrativo, mencionaba que aunque la narrativa de Meneses adoptaba formas y fórmulas propias del realismo rosado de entonces, el escritor nunca llegaría a tocar el tema político en la escritura. No deja de ser curioso por tanto, que justo cuando la narrativa de Meneses adopta sendas que niegan el sentido político de la escritura el tema aparezca; aún más, que El falso cuaderno y La misa de Arlequín puedan ser leídas también —no siendo lectura dominante - como revisión de la historia política venezolana de los años veinte al cuarenta. 
La misa de Arlequín (1962), aunque no ha sido tan bien acogida por la crítlca posterior, es una novela que inaugura el ciclo de las que entonces se llamaron novelas totales historia, política, metaficcionalidad, reflexión intimista, múltiples formas y géneroscaracterísticas del "boom". Su esquema no deja de guardar similitudes con el desarrollado diez años atrás en El falso cuaderno ... no obstante es más ambicioso y constituye un verdadero cierre en la escritura narrativa de Meneses. José Martínez y el otro yo desdoblado, el mito, Américo Arlequín - vida y literatura - son sus actores. Ambos llegan a la misma conclusión sobre el valor de la contradicción para definir la existencia y la escritura, ambas se resumen en la imagen de la muñeca rusa, que completa las visiones que Meneses venía construyendo desde 1946:

Arlequín se considera semejante a uno de esos juegos en los cuales hay una caja que contiene otra caja donde viene una caja menor y esta última guarda otra más chica, hasta llegar a una mínima caja que nada contiene ( $C n 568)$.

Esta imagen permitirá caracterizar en la novela tanto la actividad vital y escritural de ambos personajes, como la realidad concebida en términos históricos, sociales y políticos. Pero más que esto me interesa rescatar aquí la presencia apenas velada del tema político. El relato de José Martínez se dispone de tal modo que culmina en la presentación de un suceso que interrumpe la vida de la ciudad y sus habitantes, trastrocando lo que era ilusión en ruina y angustia. La narración de Arlequín retoma ese hecho para dotarlo de una dimensión histórica más amplia. El suceso, en la novela de Arlequín presentado como el "Ballet de los Coroneles", alude a la llamada Revolución de octubre de 1945, la caída del proyecto medinista. El propio Meneses, en una entrevista, revelaría el referente histórico del hecho novelesco. ${ }^{13}$ La memoria de José Martínez presenta el hecho como un "accidente" que descalifica socialmente al escritor - la resonancia autobiográfica es inevitable- y produce la caída de los personajes —en su mayoría de extracción popular-vinculados a la Sociedad de los Amigos de Dios. El personaje caracterizado sucesivamente como el Cura Verde, Arzobispo cismático, Obispo verde o falso arzobispo, emblema del político demagogo y populista, ${ }^{14}$ será presentado como responsable del accidente social. El mestizo - mito del primer Meneses- Américo Arlequín, personaje que en sus disfraces se constituye como representación de la historia continental hecha literatura 0 , mejor, farsa, al escribir su novela presenta lo que para José Martínez es "accidente" y fracaso como hecho "natural", como signo fatal de las aspiraciones sociales desde el momenlo de la Conquista hasta el presente. En el caso de la novela de Arlequín los sucesos del 45 se prolongarán en el tiempo para ofrecer la misma versión para los ocurridos en Venezuela en 1948 y 1958, caídas y resurrecciones de regímenes democráticos condenados de antemano a la inutilidad.

Esta posibilidad de lectura ha sido cuidadosamente silenciada por la crítica de Meneses, acaso porque se piense que ello pueda empañar su imagen. Ciertamente, el manejo de lo

\footnotetext{
${ }^{13}$ Emilio Santana, "La novela de Guillermo Meneses basa su intriga en el 18 de Octubre" (entrevista), El Nacional (30-8-62) 20.

${ }^{14}$ No es difícil asociar esta figura a la histórica de Rómulo Betancourt, protagonista de aquél golpe, al que Meneses siempre estuvo enfrentado desde finales de los años treinta.
} 
histórico-político es el principal Talón de Aquiles de la narrativa de Meneses — no sólo de él, por lo demás - pero sería inútil negar su presencia primero porque es evidente, y luego porque da pistas para explicar el cambio que se produjo en el proyecto narrativo del escritor a partir de 1945. Sin embargo del mismo modo que La misa de Arlequín ha sido silenciada. El falso cuaderno ... no ha dejado de recibir elogios y en ella el lector puede encontrar una alusión capital -mejor resuelta narrativamente- a un hecho histórico. El cuaderno en cuestión es la autobiografia apócrifa de Narciso adolescente que culmina en su rebelión ante el Tirano y en el Gesto de la Medalla, hechos que repiten casi puntualmente otros que Arlette Machado describiría recientemente en la biografía del escritor (Asedio a Guillermo Meneses) y que aluden inequívocamente a los sucesos del año 28 , el de la vanguardia política. Narciso es pues uno de los héroes míticos del 28. La narración del cuaderno corroe la dimensión heroica del gesto y expresa el desencanto irónicamente:

Conmovedora la escena. Graciosa en su dibujo melancólico, el hombre la mira a distancia de años y sonríe ( $C n$ 432).

... no hay razón para el compasivo carino ante el aprendiz de personaje heroico (432-33).

... opuso al mundo que lo rodeaba un pequeño pero magnífico gesto bravucón (433).

El homhre que esto escribe duda, con melancólica sonrisa, y deja su duda escrita, con tristeza cierta (433).

El final de la novela refrenda la visión del desencanto ante la historia política. Después de todo Narciso es "un hombre - uno como tantos", "Pedro Pérez - u otro nombre sin especial distinción", el fracaso del mito. Fracaso que hará olvidar los años dorados del populismo y hará tambalear un modo de entender el oficio de escribir y de presentar sus productos, para diseñar otro que - hasta hoy — tenderá a imponerse. 